\title{
Planejamento do Balanço Bancário: Desenvolvimento de um Modelo Matemático de Otimização do Retorno Econômico Ajustado ao Risco
}

\author{
Solange Garcia dos Reis \\ Doutora em Controladoria e Contabilidade pela FEA/USP \\ Mestre em Matemática pela UnB - Brasília \\ Assessora da Diretoria de Controle e Relações com Investidores do Banco do Brasil - Brasília \\ Eliseu Martins \\ Diretor da Faculdade de Economia, Administração e Contabilidade - USP \\ Professor Titular do Departamento de Contabilidade e Atuária da FEA/USP
}

RESUMO

Este trabalho consiste na concepção de um modelo matemático de otimização para auxiliar a escoIha das categorias de ativos e passivos que comporão a estrutura patrimonial de uma instituição bancária em períodos futuros.

O modelo de decisão dos gestores bancários, o qual é traduzido pelo modelo matemático, considera a necessidade de um processo de planejamento estruturado, no qual são escolhidas as alternativas que proporcionarão o maior retorno econômico e, simultaneamente, considera a necessidade de atendimento às limitações do ambiente operacional dos bancos: suas políticas internas em relação ao risco e liquidez, os relacionamentos contábeis do balanço a cada período do horizonte de planejamento, os requisitos normativos exigidos pelos reguladores bancários e as restrições relativas aos volumes de negociação suportáveis pelo mercado.

A principal restrição abordada no modelo é a limitação de capital próprio para cobertura de riscos do portfólio. Esse aspecto é contemplado da perspectiva dos reguladores, por meio da modelagem dos requerimentos normativos de capital, e da perspectiva dos gestores, por meio da proposta de utilização de um modelo estatístico para mensuração do risco.

O modelo matemático construído é caracterizado como um modelo de programação não-linear, multiperiódico e probabilístico.

Palavras-chave: Contabilidade bancária, balanço-modelos matemáticos, controle de risco
ABSTRACT

This paper is concerned with the construction of a mathematical optimization model that helps to choose the categories of assets and liabilities that will form the balance sheet of a bank in future periods.

The mathematical model herein represents a decision model for bank managers. In its assumptions, it considers the necessity of a structural planning, in which there some alternatives have to be chosen to provide a better economic return. In addition, it also considers the necessity of meeting the constraints of a bank's operational environment: politics established by the Company regarding risk and liquidity, the accounting relations in the balance sheet from each period in the planning scope, the regulatory requirements defined by banking regulators, as well as the restrictions on acceptable volumes of trade.

The major constraint in the model is the capital adequacy towards the coverage of portfolio risks. This aspect is considered not only from the regulators' perspective, which provides a formula to calculate the capital requirements, but also from the managers' perspective, represented by a suggested statistical model to measure risk.

The present mathematical model is considered to be a non-linear programming, multi-periodic and probabilistic one.

Key words: Bank accounting, balance sheet mathematical models, risk control 


\section{INTRODUÇÃO}

A maior instabilidade dos preços na economia, aliada ao incremento de competitividade e a processos mais recentes, como a internacionalização, a inovação de instrumentos financeiros e a globalização de mercados, tem exposto as instituições bancárias a um maior nível de riscos, os quais têm-se materializado através de enormes perdas financeiras ocorridas no setor nos últimos anos.

Esse cenário tem provocado um forte movimento dos reguladores em direção a controles mais específicos sobre a alavancagem dos bancos. Os órgãos reguladores têm pesadamente imposto exigências sobre manutenção de capital próprio para assegurar a capacidade das instituições em absorver as perdas decorrentes de inadimplência e, também, aquelas oriundas das possíveis oscilações no valor de mercado de seus ativos. Considerando as atuais discussões em âmbito mundial e as normatizações mais recentes, os reguladores parecem inclinados a abranger, progressivamente, os diversos riscos a que se expõe a atividade financeira, não só o risco de crédito e de mercado, como também o risco operacional e outras categorias de risco.

$\mathrm{Na}$ perspectiva interna de gerenciamento de ativos e passivos nas instituições bancárias, esse cenário tem conduzido ao desenvolvimento e aperfeiçoamento de modelos estatísticos com capacidade para mensurar, com alto grau de acurácia, os impactos das oscilações de preços e de outras variáveis sobre a margem financeira das instituições. Essa tendência propicia, por um lado, condições para a integração do objetivo gerencial de obter uma composição de ativos e passivos que exponha a instituição a um nível de risco aceitável e, por outro, que a instituição tenha capacidade para absorver as possíveis perdas que podem advir desse nível de risco considerado.

Diante dessas novas circunstâncias operacionais na atuação dos bancos, é oportuna a discussão de ferramentas auxiliares ao seu processo de planejamento e de tomada de decisão. Nesse sentido, o objetivo da proposta de um modelo matemático de otimização é auxiliar a escolha da melhor composição de ativos e passivos na estrutura do balanço do banco, respeitadas as preferências da instituição em relação ao risco e às demais limitações existentes no ambiente interno $e$ externo em que a instituição opera.

Os modelos de otimização matemática são estruturados por meio da definição de uma função objetivo que representa o retorno esperado das categorias de ativos consideradas e da definição de um conjunto de restrições que limitam a maximização desse retorno.

Considerando o objetivo de incremento da riqueza da instituição, importa questionar que tipo de medida possibilita orientação ao atingimento desse objetivo, uma vez que a incerteza derivada da passagem do tempo e das condições circunstanciais da economia pode conduzir a resultados financeiros adversos ao longo do tempo.

A maioria dos trabalhos pesquisados que tratam do desenvolvimento de uma ferramenta matemática para auxiliar o planejamento da estrutura do balanço bancário não se têm preocupado em questionar a medida de atratividade dos ativos e passivos inseridos no modelo, e que se constitui no objeto de otimização, desconsiderando a polêmica conceitual relativa a medidas orientadoras do processo decisório para obtenção de maior valor econômico. Além disso, nos modelos propostos, os autores têm sido parcimoniosos na consideração de técnicas gerenciais para mensuração de riscos, preferindo utilizar para tal propósito as restrições legais impostas pelas autoridades reguladoras ou a probabilidade de ocorrência de determinados cenários.

\section{REVISÃO DOS TRABALHOS REALIZADOS}

A utilização de modelos de Programação Matemática para resolução de problemas de decisão empresarial constitui-se na aplicação dos conhecimentos científicos oriundos, inicialmente, do campo de conhecimento da Pesquisa Operacional (PO). Nessa abordagem, a modelagem matemática corresponde à codificação do objetivo e das restrições do problema em linguagem simbólica; no caso, por meio de equações matemáticas; e a solução é obtida pela utilização de métodos sistemáticos de resolução, ou seja, por meio de algoritmos matemáticos compatíveis com a modelagem realizada.

A formulação padrão de um problema de Programação Matemática pode ser apresentada pelo seguinte modelo:

Max (ou Min)

$z=f\left(x_{1}, x_{2, \ldots,} x_{n)}(1)\right.$ 
sujeito a

$$
\begin{aligned}
& g_{i}\left(x_{1}, x_{2}, \ldots, x_{n}\right)>,=\text { ou }<b_{i}, i: 1 \ldots m(2) \\
& S=\left\{x=\left(x_{1}, x_{2}, \ldots, x_{n}\right) / g_{i}(x)>,=\text { ou }<b_{i}, i: 1 \ldots m\right\} \text { (3) }
\end{aligned}
$$

onde $x_{1}$ - são denominadas variáveis de decisão e representam as qualidades ou recursos que se quer denominar para maximizar (ou minimizar) o valor da função objetivo;

$b_{i}$ - representa,em geral, as quantidades disponíveis de cada recurso;

$\mathrm{n}$ - quantidade de variáveis de decisão do problema;

m - quantidade de restrições do problema.

e

(1) é a função matemática que codifica o objetivo do problema e é denominada função objetivo do modelo;

(2) são as equações matemáticas que codificam as restrições do problema;

(3) é o conjunto de soluções viáveis do problema. Qualquer solução viável x*, que torna o valor da função z máximo (ou mínimo), é considerada uma solução ótima para o problema.

Se a função objetivo ( $\mathrm{fx}$ ) e as $m$ restrições $\mathrm{g}_{\mathrm{i}}(\mathrm{x})$ são representadas por funções lineares,o modelo é classificado como sendo um modelo de Programação Linear (PL).Se pelo menos uma das funções não é linear, então o modelo é classificado como um modelo de Programação Não-Linear (PNL). Nos modelos probabilísticos, é considerada a distribuição de probabilidades de uma ou mais variáveis do problema, e nos modelos determinísticos pressupõe-se que os dados são obtidos com certeza.

A proposição de modelos de Programação Matemática para o planejamento bancário teve início na década de 60 (CHAMBERS E CHARNES, 1961) e apresentou grandes impulsos nas décadas de $70 \mathrm{e}$ 80. Nesse trabalho pioneiro, o problema apresentado é a determinação da composição ótima de ativos que maximiza o lucro gerado pelo banco durante um horizonte temporal multiperiódico (com múltiplos períodos). A escolha entre os ativos considera, em cada período, o atendimento a dois tipos de restrições: a manutenção de reservas líquidas e o limite de alavancagem. A formulação da restrição de alavancagem ${ }^{1}$ é derivada do conjunto de medidas regulatórias relativas à adequação de capital utilizadas, à época, pelo FED - Federal Reserve Board².

O modelo matemático construído para o problema é linear e determinístico. A aplicação do modelo é ilustrada no desenvolvimento de um exemplo com 6 (seis) variáveis de decisão e um horizonte temporal de 5 (cinco) períodos. O lucro de cada alternativa de investimento é considerado como um dado conhecido do problema, sob a premissa de que o banco é capaz de estimar com certeza o lucro líquido de cada tipo de ativo em cada período do horizonte temporal de planejamento. O lucro líquido é entendido como o recebimento de juros periódicos, líquidos de qualquer custo que poderia ser alocado ao ativo.

Uma restrição final é definida considerando-se os fundos totais disponíveis para aplicação nos ativos. Os investimentos totais, em qualquer período, não podem exceder o somatório dos recursos provenientes do vencimento de títulos comprados anteriormente, mais o crescimento do patrimônio líquido do banco e o aumento líquido dos depósitos em relação ao período anterior.

No trabalho de COHEN e HAMMER (1967) é descrito o modelo desenvolvido e implementado pelo grupo de Ciências da Administração (Management Science) do Bankers Trust Company, o qual, há vários anos, já vinha sendo utilizado como ferramenta no processo de administração do balanço do Banco. Trata-se de um modelo de programação linear multiperiódico e determinístico, cuja função objetivo busca maximizar o valor presente dos fluxos de recursos que se esperam ao longo dos múltiplos períodos do horizonte de planejamento.

São discutidas restrições relativas às políticas internas, a aspectos econômicos e institucionais e a uma variedade de efeitos dinâmicos que podem ser incluídos pela administração. As restrições de políticas internas referem-se à modelagem de determinados relacionamentos percentuais entre categorias de ativos e obrigações que, embora reconhecidamente sejam medidas limitadas, são incluídas no modelo por se-

\footnotetext{
${ }^{1}$ Como conseqüência do Acordo da Basiléia (BASLE COMMITTEE ON BANKING SUPERVISION 1988) não existem mais restrições legais relativas a limites de alavancagem em relação à captação. $O$ controle de riscos das instituições financeiras pelos reguladores foi transferido dos itens do passivo para os itens do ativo.

${ }^{2} \mathrm{O}$ FED é o banco central dos Estados Unidos e o órgão regulador do sistema financeiro americano.
} 
rem usualmente praticadas pelo mercado e interpretadas como padrões aceitáveis pelos acionistas e depositantes. A liquidez e a alavancagem são contempladas em restrições que seguem o critério proposto pelos reguladores do $F E D$, nos mesmos termos utilizados por CHAMBERS e CHARNES (1961). Restrições sobre a dinamicidade das operações envolvem relações mais específicas do processo operacional dos bancos, que podem ser incluídas no modelo; por exemplo, é sugerida a modelagem de exigências de manutenção de lastro para depósitos do governo por meio da definição de percentuais de relacionamento entre títulos governamentais comprados e vendidos.

O trabalho de BRODT (1978) ilustra a aplicação dos princípios da Teoria do Portfólio num planejamento multiperiódico e de longo prazo. Com base no critério de decisão usado na seleção de portfólios de MARKOWITZ ${ }^{3}$ (1959), o autor desenvolve um modelo de programação linear e probabilístico para definir a composição de ativos e obrigações no balanço de um banco canadense. Dada uma posição inicial do balanço do banco e um conjunto de restrições, são considerados vários cenários e a probabilidade de ocorrência de cada um deles. O modelo fornece, dada uma meta de lucros esperada, o conjunto eficiente de decisões para o horizonte de planejamento considerado, ou seja, as decisões sobre os montantes de cada categoria de aplicação e captação, em cada período, as quais proporcionam o menor nível de risco.

Em relação às características matemáticas do modelo de MARKOWITZ, a formulação de BRODT inova ao considerar a multiperiodicidade e a medida estatística de risco como desvios médios absolutos, isto é, como a soma dos desvios absolutos dos possíveis lucros em relação a um lucro médio esperado (em termos de probabilidade). No modelo de MARKOWITZ é utilizado um horizonte temporal de um único período (monoperíodo) e a medida de risco é a variância dos retornos. A substituição da medida de risco é sustentada por argumentos teóricos e práticos. A razão prática é que, mediante uma transformação matemática, o modelo pode ser resolvido utilizando a programação linear padrão, enquanto na proposição inicial a aplicação do método de resolução é mais complicada, necessitando de técnicas de programação quadrática. Do ponto de vista teórico, o autor demonstra que os portfólios obtidos pela aplicação de cada um dos dois métodos de resolução são idênticos sob a hipótese de que a distribuição estatística de freqüência dos retornos é normal.

RODRIGUES (1991), em sua dissertação de Mestrado, desenvolve um modelo de programação linear determinístico e multiperiódico para aplicação no planejamento financeiro de um pequeno banco múltiplo brasileiro e utiliza-o em conjunto com um modelo de simulação.

O objetivo do modelo de otimização é o fornecimento da composição de ativos, obrigações e capital próprio do banco que maximiza seus lucros ao longo do horizonte de planejamento constituído de 12 períodos mensais. O modelo de simulação desenvolvido busca integrar e comparar a solução obtida por um processo de planejamento simples, que utiliza um modelo simulador de balanços e demonstrações de resultados, com a solução fornecida pela aplicação conjunta do modelo de simulação e do modelo de programação linear. A conclusão do trabalho é de a utilização da ferramenta de otimização matemática pode efetivamente aprimorar o processo de planejamento e tomada de decisão no ambiente bancário brasileiro.

O conjunto de restrições formulada procura captar as limitações relativas aos aspectos contábil, legal e operacional das atividades bancárias. As restrições contábeis consideram a equação fundamental de equilíbrio entre ativos e passivos, bem como a formação do capital de giro próprio e do patrimônio líquido em cada período. As restrições legais incluem a incidência de impostos (PIS e FINSOCIAL), a alavancagem derivada da relação exigida entre o patrimônio líquido e o montante de captação de recursos de terceiros, os limites de diversificação por categoria de operações, as necessidades de aplicações compulsórias em ativos financeiros e o encaixe compulsório. As restrições operacionais descrevem as projeções quanto aos limites máximos e mínimos relativos aos comportamento

\footnotetext{
${ }^{3}$ O trabalho de composição de carteiras apresentado por MARKOWITZ (1959) desenvolve os princípios básicos da moderna Teoria do Portfólio. O critério de decisão corresponde à escolha do portfólio que oferece o menor nível de risco dado um retorno esperado, ou o maior retorno dado um nível de risco aceitável. Esta combinação entre retorno e risco pode ser representada graficamente por uma hipérbole que é denominada fronteira eficiente. A formulação matemática do problema de seleção de carteiras de MARKOWITZ é representada por um modelo de programação quadrática.
} 
do mercado, no tocante à demanda por determinados ativos ou à oferta de categorias de captações. Também são incluídas restrições denominadas pelo autor de políticas de operação. Essas restrições expressam o julgamento da administração com relação ao estabelecimento de limites máximos para a captação de recursos em cada categoria de ativo financeiro, bem como à determinação de limites mínimos abaixo dos quais o banco não está disposto a operar.

O trabalho de GÜVEN e PERSENTILI (1997) é o mais recente a que tivemos acesso e trata do desenvolvimento e da análise de desempenho de um modelo de programação linear. O principal objetivo do trabalho é demonstrar a vantagem de utilização de um modelo de programação matemática como ferramenta de planejamento bancário por intermédio da análise de seu desempenho ex-post. Os autores desenvolvem um modelo para determinar o tamanho e a composição dos ativos e obrigações de um grande banco comercial da Turquia, aplicando-o de forma retrospectiva ao período de 1987 a 1990. O desempenho real do banco durante os 4 anos passados é comparado com o desempenho que teria sido obtido pela utilização do modelo matemático. Os resultados apresentados demonstram a relevância do modelo como ferramenta de planejamento.

O modelo construído por GÜVEN e PERSENTILI é determinístico, linear, e define a seqüência ótima de posições do balanço no horizonte de planejamento multiperiódico de 4 anos, subdivididos em 48 períodos mensais. A função objetivo do modelo busca maximizar o valor presente do lucro líquido contábil total do banco durante o horizonte temporal, considerando as restrições legais, de liquidez, os fluxos e influxos periódicos de recursos, bem como as relações entre as contas do balanço definidas pelas políticas internas da administração.

Outras formas alternativas de abordagem são sugeridas na bibliografia pertinente. Alguns autores (por exemplo: ECHOLS e ELLIOT, 1976; BALBIRER e SHAW, 1981) enfatizam a necessidade de integração dos modelos de alocação com os modelos econométricos de previsão de taxas de juros, de níveis de empréstimos e depósitos e de estimativas de liquidez. McKINNEY JR. (1976, p.127) também sugere que o desenvolvimento dos modelos de otimização deveria buscar atender a objetivos mais específicos, traduzidos em modelos de menor porte, e procurando incluir a conjugação de vários outros modelos.

$\mathrm{Na}$ perspectiva da fundamentação teórica, os modelos estudados enfatizam o tripé rentabilidade, liquidez e risco. O objetivo de rentabilidade é representado de diversas formas; alguns o traduzem pela maximização de lucros mensurados de acordo com os princípios de contabilidade; outros o fazem por meio da maximização da margem líquida de juros, considerando somente os ativos financeiros, ou considerando os ativos e passivos financeiros. Em alguns modelos, os lucros contábeis periódicos ou a margem financeira das operações são descontados a valor presente e, em muitos casos, os trabalhos não deixam claro como essa rentabilidade é mensurada, mencionando somente os termos retorno, atratividade ou lucro.

A necessidade de liquidez é abordada conforme exigências legais e arbitrada pela administração. Outros modelos sugerem o tratamento de previsão de liquidez por meio de técnicas quantitativas.

$\mathrm{Na}$ maioria dos casos, o risco é tratado genericamente, quanto ao atendimento a percentuais definidos pelas autoridades bancárias para suportar riscos de liquidez ou de insolvência; em alguns casos, é considerado como parte das políticas de operação da instituição por meio da definição de limites máximos e mínimos de captação e aplicação em determinados produtos. Embora algumas propostas incorporem a incerteza por meio da consideração de cenários probabilísticos, a introdução de aspectos relacionados com a administração de riscos específicos das alternativas, como o risco de taxas de juros, o risco de mercado ou risco de crédito, não é, em geral, considerada. Poucas referências são encontradas na bibliografia acerca da tentativa de integrar técnicas mais analíticas de gerenciamento de ativos e passivos nos modelos de planejamento de balanços.

\section{MODELO DE DECISÃO}

O aspecto mais relevante no processo de modelagem de um problema real consiste na identificação do modelo de decisão que será representado no modelo matemático a ser construído. A definição sobre a composição de ativos e passivos financeiros de um banco pode ser caracterizada como um processo de decisão complexo que envolve a escolha de múltiplas alternativas, com múltiplos relacionamen- 
tos, consideradas num horizonte de planejamento multiperiódico e caracterizado pela incerteza, além de exigir o atendimento a diversas restrições e limitações de recursos.

Nesse sentido, a modelagem requer a discussão sobre qual é o objetivo que se pretende atingir, quais são as alternativas disponíveis e, conseqüentemente, qual é a medida mais coerente de retorno de cada alternativa para compor a função objetivo dos gestores bancários,. além da consideração sobre a possibilidade de variação nesse retorno e das demais restrições relevantes do ambiente bancário.

\subsection{Retorno Econômico}

Considerando o planejamento como um processo antecipado de tomada de decisão sobre os planos financeiros que serão executados ao longo de períodos futuros, uma proposição lógica é que esses planos deveriam ser considerados segundo os benefícios econômicos que podem proporcionar à instituição. $\mathrm{Na}$ perspectiva de uma administração voltada para o objetivo econômico de maximização da riqueza dos proprietários, o modelo de decisão deve ser orientado pelo critério de incremento de valor. Essa consideração exige, de acordo com a análise econômica de investimentos ${ }^{4}$, que as alternativas disponíveis, que são objeto do planejamento periódico, sejam analisadas de acordo com seus fluxos de caixa descontados a valor presente. Essa medida representa o que denominamos de retorno econômico esperado.

A função objetivo do modelo de decisão dos gestores bancários deve corresponder à maximização do valor presente líquido esperado (VPL) das diversas alternativas de aplicação e captação de recursos. Tanto as decisões sobre o volume de produtos de aplicação, que podem ser vistas como típicas alternativas de investimento, como as decisões sobre os volumes de produtos de captação, que genericamente podem ser vistas como alternativas de financiamento com capital de terceiros, podem ser caracterizadas como decisões separadas, sobre as quais o banco possui a oportunidade de auferir benefícios econômicos.
No método do VPL são utilizadas taxas de desconto diferenciadas para descontar os fluxos de caixa futuros de cada alternativa, compatíveis com os seus respectivos níveis de risco. Para obtenção dessas taxas é necessário que a instituição disponha de instrumental quantitativo e de

informações para construção de curvas de taxas de juros de mercado ${ }^{5}$ e, especialmente, para definição de classificações internas de qualidade de crédito de suas operações (ratings de crédito). Isso ocorre porque a maior proporção de sua carteira é composta por títulos não negociáveis, representados por empréstimos e depósitos, os quais não possuem uma taxa de oportunidade no mercado como parâmetro de comparação para os seus fluxos de caixa.

\subsection{Risco}

O aspecto de incerteza do processo decisório, que é um tipo específico de limitação, deve ser considerado no modelo uma vez que há a possibilidade de variação no retorno econômico esperado das diversas alternativas. A consideração dessa restrição complementa o critério de decisão definido pela função objetivo, incorporando a necessária análise da relação risco e retorno no processo de decisão. Assim, o critério de decisão do modelo incorpora a possibilidade de variação no VPL esperado do conjunto de alternativas, ou seja, o risco quanto à efetivação dos fluxos futuros de caixa esperados.

Para mensuração desse risco é sugerida uma adaptação do método VaR Paramétrico ${ }^{6}$. Esse método tem sido apresentado na bibliografia para a mensuração da exposição ao risco de mercado de uma carteira de negócios. O método VaR Paramétrico fornece uma medida de risco (VaR) que expressa, em unidades monetárias, a perda máxima provável de uma posição ou carteira, em determinado período, com certo grau de probabilidade. A medida depende das oscilações nos fatores de mercado que influenciam o valor das posições através do estudo das suas distribuições de freqüências estatísticas. $O$ método considera que a distribuição de freqüência das variações de taxas e preços pode ser aproxima-

\footnotetext{
${ }^{4}$ Martins e Assaf Neto (1985).

${ }^{5}$ Corresponde à representação gráfica da relação entre os prazos e as expectativas de taxas futuras determinantes do valor do ativo ou passivo sob avaliação. A curva fornece o custo corrente de capital para cada prazo considerado e baseia-se nas taxas de remuneração dos títulos governamentais considerados altamente negociáveis e isentos de riscos de inadimplência.Também é denominada curva básica de desconto ou estrutura temporal de taxas de juros. Ver também, FABOZZI(1996) e SECURATO(1999).

${ }^{6}$ RiskMetricsTM - Technical Document: Morgan Guaranty Trust Company(1995).
} 
da por uma distribuição normal e a sua volatilidade representada pela medida de desvio-padrão.

A aplicação do método VaR paramétrico no modelo de otimização proposto, fornece uma medida de risco que permite estimar o montante máximo de variação nos fluxos de caixa futuros esperados. Como esses fluxos de caixa são descontados pelas suas respectivas taxas de oportunidade, a magnitude dessa variação depende da volatilidade dessas taxas de desconto.

A introdução desse método no modelo de decisão permite a escolha do conjunto de alternativas que proporciona o maior retorno econômico possível, dado um volume de comprometimento de capital considerado aceitável. Nesse caso, a restrição de risco pode ser formulada considerando como limite um percentual do montante de capital da instituição.

\section{REQUISITOS PARA A MODELAGEM DO PROBLEMA}

Conceitualmente, um modelo constitui-se em uma representação simplificada e abstrata de uma realidade complexa. Conseqüentemente, todo processo de modelagem matemática de um problema real envolve a consideração de diversas hipóteses simplificadoras para possibilitar a sua operacionalização. A seguir são apresentadas algumas definições consideradas no desenvolvimento da modelagem matemática proposta neste trabalho.

\subsection{Construção de Categorias}

Os bancos dispõem de um amplo conjunto de alternativas de investimento, as quais podem ser consideradas na análise da composição de seu portfólio de negócios. Essas alternativas apresentam características diferenciadas quanto a prazos de vencimento, taxas de remuneração, moedas, riscos, distribuição de seus fluxos ao longo do tempo, além de aspectos peculiares de sua negociação, como, por exemplo, compromissos de recompra ou revenda, características de opcionalidade, entre outras.

Para o propósito de implementação do modelo matemático (como seria impossível considerar todos os tipos e peculiaridades das alternativas existentes), uma primeira tarefa é a escolha de categorias agregadas de ativos e passivos, as quais deverão ser contempladas na modelagem. Essas categorias devem incluir as vari- áveis de decisão cujos volumes serão obtidos pelo processo de otimização, e as variáveis que terão seus volumes obtidos por meio de previsões.

O critério de agregação das variáveis de decisão pode simplesmente corresponder a uma classificação dos produtos bancários conforme a sua relevância para a instituição, quanto a volumes negociados ou algum outro critério, levando em consideração os seus prazos médios de vencimento, como por exemplo, títulos governamentais de 30,60 e 90 dias e CDC de 60 dias (definição de 4 categorias de variáveis). No entanto, no modelo proposto neste trabalho é fundamental considerar, adicionalmente, uma definição sobre as diversas formas em que os fluxos de caixa podem distribuir-se ao longo do tempo e sobre a classificação de risco das alternativas; por exemplo: títulos de 30 dias com risco A e B; títulos de 90 dias com risco $\mathrm{A}, \mathrm{B}$ e $\mathrm{C}$; títulos descontados de 60 dias com risco $\mathrm{B}$, e títulos de 60 dias com risco $\mathrm{B}$ e recebimento de juros em 30 dias e o principal na maturidade ( 7 categorias de variáveis).

Uma quase unanimidade é encontrada na bibliografia em relação à desconsideração de títulos ativamente negociados (operações de trading) como variáveis de decisão nos modelos de programação matemática para o propósito de planejamento de médio ou longo prazo em instituições bancárias.

Assim, as categorias de produtos escolhidos devem ser aquelas cujos prazos e características de negociação indiquem a intenção de maior permanência no balanço da instituição.

As alternativas que são objeto de negociação diária geralmente são tratadas por modelos de gerenciamento mais específicos e mais sofisticados, os quais, usualmente, são geridos pela área financeira da instituição. Também os ativos usados circunstancialmente com o objetivo de proteção ou especulação, como os derivativos (Opções, Futuros e Swaps), devem ser tratados por modelos específicos.

Outros produtos bancários, como depósitos à vista e cadernetas de poupança, dada a maior dinamicidade de oscilação de seus volumes, têm sido preferencialmente tratados nos modelos como variáveis cujos montantes são obtidos por previsões. Os métodos de previsão associam os montantes historicamente negociados pela instituição com o comportamento de variáveis macroeconômicas, podendo ser utilizadas técnicas baseadas em julgamentos da ad- 
ministração ou em métodos econométricos ${ }^{7}$. Idealmente os métodos de previsão também devem ser integrados ao modelo de otimização.

\subsection{Definição do Horizonte Temporal}

A definição do horizonte de tempo que será considerado pelo modelo também é uma tarefa que exige acurada observação por parte do modelador. Um dos fatores mais importantes nessa definição é o comportamento de estabilidade ou instabilidade da economia. Como o objetivo do modelo é encontrar futuras composições ótimas do balanço sobre um horizonte de planejamento, utilizando dados como taxas básicas de juros, exigência de reservas legais, demandas por recursos, taxas de remuneração de depósitos, títulos, empréstimos, entre outros, os seus resultados serão mais válidos à medida em que se possam obter previsões confiáveis dos dados de entrada necessários ao seu processamento.

Outro fator que influi na definição do horizonte temporal do modelo é a prática bancária em relação ao período abrangido pelo planejamento e orçamento da instituição, além dos períodos definidos para apuração dos resultados financeiros. No ambiente bancário brasileiro, é usual a consideração do horizonte de um ano subdividido em períodos mensais intermediários.

\subsection{Data Focal}

A característica de dinamicidade da negociação bancária faz que sejam produzidos fluxos contínuos de entradas e saídas de recursos, ou seja, em qualquer dia do mês ocorrem vencimentos de títulos, amortizações de empréstimos, pagamentos de juros e tarifas, etc. Para maior simplicidade na operacionalização é necessário, contudo, discretizar o modelo, definindo uma data focal para cálculo dos fluxos e influxos de recursos financeiros provenientes das operações.

A data focal não precisa necessariamente ser coincidente com os pontos de decisão do modelo momentos definidos para o planejamento das operações futuras. Por simplificação, as fórmulas podem ser descritas considerando-se a coincidência, ou seja, pontos de decisão no início dos períodos e data focal também no início, assumindo-se o vencimento e a contratação de novas operações sempre no primeiro dia do mês; contudo, se a suposição for desconsiderada, a tarefa adicional é utilizar a matemática financeira para capitalizar ou descapitalizar os fluxos e influxos de recursos ocorridos dentro do mês até o início do período seguinte.

\subsection{Consideração de outras Receitas e DESPESAS}

No cálculo do retorno das alternativas de investimento são consideradas as taxas de remuneração contratuais negociadas nas operações financeiras, ou seja, a receita e a despesa da intermediação financeira descontadas a valor presente. Em uma abordagem de formulação mais analítica dos fluxos de caixa gerados pelas operações, pode-se considerar que esses são afetados pelo incremento de outras receitas de tarifas e serviços que podem ser geradas.

Obviamente, a realidade da atividade bancária indica existirem vinculações entre a negociação de ativos e passivos e as receitas de serviços que esses proporcionam à instituição, além de vinculações mais difíceis de se evidenciar com os custos relativos ao consumo de estrutura, como mão-de-obra, equipamentos, etc. As vinculações entre receitas da intermediação financeira e receitas de serviços, embora introduzindo maior complexidade, são passíveis de ser consideradas no modelo de otimização, desde que a instituição disponha de séries históricas que permitam algum tipo de tratamento matemático desses dados. Quanto ao consumo de estrutura, por possuir característica de custo indireto ${ }^{8}$, é recomendável manter a suposição de que é definido por estratégias mais amplas da organização e que seus montantes suportam determinados volumes de operações dentro do período considerado.

\subsection{Modelagem das Restrições}

Na definição das restrições do modelo, também é necessária a construção de categorias que reflitam a relevância e representatividade das limitações existentes no negócio bancário. No modelo proposto, são definidos 12 (doze) tipos de restrição, considerando

\footnotetext{
${ }^{7}$ GÜVEn \& Persentili (1997) utilizam modelos econométricos de regressão múltipla.

${ }^{8}$ Custo não identificável de maneira direta à unidade de produto senão por medidas estimadas ou arbitrárias.
} 
a integração de 4 (quatro) aspectos essenciais da gestão bancária: as preferências da instituição; a lógica dos relacionamentos contábeis; as imposições legais e as condições do mercado.

As preferências da instituição compreendem os limites definidos pelos administradores em relação aos limites de risco e liquidez considerados suportáveis. $O$ modelo contempla a restrição quanto ao risco de variação no valor presente líquido das alternativas sob escolha, o limite máximo de risco de crédito obtido por modelos gerenciais e o limite mínimo a ser mantido como reserva de liquidez. Os relacionamentos contábeis compreendem o equilíbrio entre ativos e passivos e o ajustamento, a cada período, do patrimônio líquido da instituição. As imposições legais consideradas referem-se à constituição de reservas compulsórias e aos limites de imobilização e capitalização do banco. As restrições de mercado correspondem aos limites máximos e mínimos de captação e aplicação para cada alternativa existente.

Dentro dessas categorias poderiam ser consideradas diversas outras restrições que a administração julgasse necessárias, como por exemplo, relacionamentos contábeis mais detalhados entre as posições patrimoniais, características empíricas do ambiente ou mesmo do estilo dos administradores; no entanto, quanto maior a quantidade de restrições, maior é também o volume de dados necessários ao processamento do modelo, além da possibilidade de se introduzirem restrições que se contrapõem, ou seja: o atendimento de uma inviabiliza o atendimento da outra, impossibilitando a obtenção de uma solução para o problema modelado.

Outra situação é a sobreposição de restrições; por exemplo, o volume de capital exigido na restrição legal para atender aos requisitos de adequação de capital poderia ser inferior àquele exigido na restrição de risco do modelo gerencial. Como o método de resolução do modelo trabalha com o atendimento simultâneo das restrições, a solução obtida deixaria ainda, do ponto de vista legal, margem para alavancagem da instituição.

Esses aspectos devem ser objeto de análise após a etapa de resolução do modelo (pós-otimização), podendo exigir a reformulação de determinadas restrições ou de parâmetros utilizados inicialmente na modelagem. A incorporação de ajustes no modelo também pode ser realizada por meio da análise de sensibilidade. A análise de sensibilidade do modelo permite verificar o comportamento da solução obtida a partir de pequenas variações nos dados de entrada do modelo, como coeficientes da função objetivo, coeficientes das restrições ou limites definidos para as restrições.

Do ponto de vista legal é difícil flexibilizar qualquer restrição; contudo as restrições que dependem da preferência da instituição podem ser modificadas conforme o tradeoff que significará, por exemplo, um esforço adicional para superar um limite de captação em relação ao incremento que isso pode provocar no resultado econômico.

\subsection{Utilização de Metodologias e Técnicas AuxiLIares}

Para obter os coeficientes da função objetivo, utiliza-se o método do valor presente, o qual exige a consideração das características específicas de cada ativo quanto aos seus fluxos de caixa esperados e às taxas de desconto adequadas para tal. Para tanto, é necessário que a instituição disponha de informações sobre o perfil de risco e a periodicidade dos retornos e desembolsos das categorias de alternativas consideradas no modelo.

A obtenção das taxas de desconto representativas do risco de cada alternativa exige a utilização de técnicas adequadas para a construção de curvas de taxas. Nesse sentido, outro aspecto peculiar que é introduzido no modelo é a necessidade de integração com modelos econométricos para previsão de taxas de desconto - construção das curvas de taxas de juros e de spreads de risco de crédito. Para as operações que apresentam risco de inadimplência, a utilização dos modelos de risco de crédito são essenciais para a aplicação do modelo de otimização proposto, exigindo um considerável esforço interno do banco para construção de ratings de crédito baseados no risco do cliente, na natureza da operação, no setor de atividade em que a empresa se insere, entre outros aspectos.

Para formalização da restrição de risco, a qual considera a possibilidade de variação na riqueza proporcionada por cada conjunto de alternativas disponíveis, é considerada a utilização do modelo VaR Paramétrico. A aplicação do método exige a mensuração da exposição das posições do banco aos seus respectivos fatores de risco - as suas taxas de desconto -, da sensibilidade da exposição, bem como da volatilidade e correlação entre as taxas. 
As demais variáveis definidas serão necessárias para contemplar as relações intertemporais (relativas a cada período) e as relações intratemporais (entre os períodos) que ocorrerão no balanço bancário ao longo do horizonte de planejamento. Os volumes dessas variáveis serão obtidos por meio de estimativas (por exemplo, para $D V, C P$ e $A P$ ) ou determinados pelas restrições e mudanças endógenas ocorridas no balanço da instituição ao longo dos períodos (por exemplo, para $R C, R L$ e $P L$ ). Como pressuposto é considerado que esses volumes financeiros são apresentados em moeda de capacidade aquisitiva constante.

Na representação das variáveis de decisão do modelo, além da identificação do tipo de ativo (subscrito i) e do momento da tomada de decisão (subscrito J), são introduzidos, como caracterização adicional, o perfil $p=(l, k)$ e o índice $q$. O perfil $p$ fornece informações sobre os prazos e a quantidade de fluxos de caixa das alternativas de aplicação e captação. $O$ índice $q$ indica a classificação quanto à qualidade de crédito do cliente, da contraparte ou da operação nas alternativas de aplicação.

A matriz de perfis $p(I, k)$, apresentada na TABELA 2, ilustra as características de maturidade (índice $k$ ) e a quantidade (índice I) de fluxos de pagamentos e recebimentos prometidos nas operações contratadas.

TABELA 2 - $\quad$ Matriz de perfis - $p(I . k)$

\begin{tabular}{|c|c|c|c|c|c|c|c|c|}
\hline $\begin{array}{c}\text { QuANTIDADE } \\
\text { DE } \\
\text { FLUXOS }\end{array}$ & $\mathbf{1}$ & $\mathbf{2}$ & $\mathbf{3}$ & $\mathbf{4}$ & $\mathbf{. .}$ & $\mathbf{~}$ & $\mathbf{. .}$ & $\mathbf{~}$ \\
\hline 1 & $(1,1)$ & $(1,2)$ & $(1,3)$ & $(1,4)$ &.. & $(1, \mathrm{k})$ &.. & $(1, \mathrm{~K})$ \\
2 & & $(2,2)$ & $(2,3)$ & $(2,4)$ &.. & $(2, \mathrm{k})$ &.. & $(2, \mathrm{k})$ \\
3 & & & $(3,3)$ & $(3,4)$ &.. & $(3, \mathrm{k})$ &.. & $(3, \mathrm{k})$ \\
4 & & & & $(4,4)$ &.. & $(4, \mathrm{k})$ &.. & $(4, \mathrm{k})$ \\
.. & & & & &.. &.. &.. &.. \\
I & & & & & & $(\mathrm{I}, \mathrm{k})$ &.. & $(\mathrm{I}, \mathrm{k})$ \\
.. & & & & & & &.. &.. \\
$\mathrm{L}$ & & & & & & & & $(\mathrm{L}, \mathrm{K})$ \\
\hline
\end{tabular}

Teoricamente, as operações podem ser caracterizadas por todos os perfis acima da diagonal da matriz; contudo, por simplificação, a modelagem proposta considera operações com um único fluxo e várias maturidades (linha $(1, \mathrm{k}), \mathrm{k}: 1 . . \mathrm{K}$ ) e operações onde a maturidade e o número de fluxos são coincidentes (diagonal (k,k), k:1..K). Também, como hipótese simplificadora, considera-se que as negociações sempre ocorrem no início dos períodos e têm seu vencimento no final deles.

Para classificação das operações em relação à qualidade de crédito $q$, a instituição pode dispor de ratings definidos para os títulos negociáveis e de metodologias desenvolvidas internamente para avaliação de seus ativos ilíquidos (não negociáveis).

\subsection{Função Objetivo}

A função objetivo do modelo traduz o propósito de maximização de riqueza, utilizando como medida de atratividade de cada alternativa individual os seus fluxos de caixa futuros descontados a valor presente. Assim, o critério de decisão descrito pela função objetivo do modelo orienta a escolha do conjunto de alternativas que produz o maior VPL, considerando as diversas alternativas de aplicação e de captação disponíveis a cada período do horizonte de planejamento: 


$$
\operatorname{Max} \_\mathbf{Z}=\sum_{i=1}^{N} \sum_{j=1}^{T} V P L_{i j}^{A}+\sum_{i=1}^{M} \sum_{j=1}^{T} V P L_{i j}^{P}
$$

Onde? $V P L_{i j}^{A}=S_{i j}^{p q} X_{i j}^{p q}$ e $\quad V P L_{i j}^{P}=R_{i j}^{p} Y_{i j}^{p}$

$S_{i j}^{p q}:$ Fator de valor presente líquido do ativo $i$, no momento $j$, com o perfil $p=(l, k)$ e a qualidade de crédito $q$;

$X_{i j}^{p q}$ : Volume do ativo $i$, no momento $j$, com o perfil $p=(l, k)$ e a qualidade de crédito $q$;

$R_{i j}^{p}$ : Fator de valor presente líquido do passivo $i$, no momento $j$, com o perfil $p=(l, k)$;

$Y_{i j}^{p}$ : Volume do passivo $i$, no momento $j$, com o perfil $p=(l, k)$;

$N$ : Quantidade de ativos;

$M$ : Quantidade de passivos;

$T$ : Quantidade de períodos (meses) do horizonte de planejamento.

Para determinar a taxa de desconto dos fluxos das operações, são utilizadas estimativas das taxas livres de risco e das taxas de remuneração do risco de crédito. A representação dessas taxas é apresentada na TABELA 3.

TABELA 3. Taxas livres de risco

\begin{tabular}{|c|c|c|c|c|c|c|c|}
\hline \multirow{2}{*}{ MOMENTO $j$} & \multicolumn{7}{|c|}{ Maturidade } \\
\hline & 1 & 2 & 3 & $\ldots$ & $k$ & $\ldots$ & $K$ \\
\hline 1 & $r_{1}^{(1)}$ & $r_{1}^{(2)}$ & $r_{1}^{(3)}$ & $\cdots$ & $r_{1}^{(k)}$ & $\ldots$ & $r_{1}^{(K)}$ \\
\hline 2 & $r_{2}^{(1)}$ & $r_{2}^{(2)}$ & $r_{2}^{(3)}$ & $\ldots$ & $r_{2}^{(k)}$ & $\ldots$ & $r_{2}^{(K)}$ \\
\hline 3 & $r_{3}^{(1)}$ & $r_{3}^{(2)}$ & $r_{3}^{(3)}$ & $\cdots$ & $r_{3}^{(k)}$ & $\ldots$ & $r_{3}^{(K)}$ \\
\hline .. & $\cdots$ & $\ldots$ & $\cdots$ & $\cdots$ & $\cdots$ & $\cdots$ & $\cdots$ \\
\hline$T$ & $r_{T}^{(1)}$ & $r_{T}^{(2)}$ & $r_{T}^{(3)}$ & $\cdots$ & $r_{T}^{(k)}$ & $\ldots$ & $\boldsymbol{r}_{T}^{(K)}$ \\
\hline
\end{tabular}

No momento de planejamento das decisões, ou seja, para $j=1$, as taxas $r_{1}{ }^{(k)}$ são as taxas a vista para os diversos períodos $\mathrm{k}$, obtidas pela Curva Básica de Desconto. No planejamento das decisões futuras, ou seja, para $j>1$, as taxas $r_{j}^{(k)}$ são as taxas futuras (implícitas) obtidas por meio da referida Curva.

Para cada classificação de qualidade de crédito considerada pela instituição deve ser associado um spread, ou prêmio, pela probabilidade de inadimplência da contraparte. A TABELA 4 descreve as taxas ${ }_{S}{ }^{(O K)}$ que representam os prêmios pelo risco de crédito das operações contratadas no momento j, com a classificação de qualidade de crédito q e maturidade $\mathrm{k}$ 
Tabela 4. Classificação da Qualidade dos Ativos - Prêmios de Risco

\begin{tabular}{|c|c|c|c|c|c|c|c|}
\hline \multirow{2}{*}{ Qualidade } & \multicolumn{7}{|c|}{ MatuRIDADE } \\
\hline & 1 & 2 & 3 & $\ldots$ & k & $\ldots$ & K \\
\hline 1 & $S^{(11)}$ & $S^{(12)}$ & $S^{(11)}$ & $\ldots$ & $S^{(1 k)}$ & $\ldots$ & $S^{(1 K}$ \\
\hline 2 & $S^{(21)}$ & $S^{(22)}$ & $S^{(23)}$ & $\ldots$ & $S^{(2 k)}$ & $\ldots$ & $S^{(2 K}$ \\
\hline$\cdots$ & $\ldots$ & $\ldots$ & $\ldots$ & $\ldots$ & $\cdots$ & $\ldots$ & $\cdots$ \\
\hline$q$ & $S^{(q 1)}$ & $S^{(q 2)}$ & $S^{(q 3)}$ & & $S^{(q k)}$ & & $S^{(q K}$ \\
\hline$\cdots$ & $\cdots$ & $\cdots$ & $\cdots$ & $\ldots$ & $\cdots$ & $\ldots$ & $\ldots$ \\
\hline $\mathbf{Q}$ & $S^{(Q 1)}$ & $S^{(Q 2)}$ & $s^{(Q 3)}$ & $\ldots$ & $s^{(Q k)}$ & $\ldots$ & $S^{(Q K}$ \\
\hline
\end{tabular}

Assim, como exemplo, para operações com um único fluxo ou com pagamentos periódicos de remuneração/encargos financeiros temos as seguintes expressões para o cálculo dos fatores de valor presente líquido dos ativos e passivos:

Fluxo Único $(p=(L, K), L=1)$

$$
S_{i j}^{p q}=\frac{\left(1+a_{i j}\right)^{K}}{\left(1+r_{j}^{(K)}+s_{j}^{(q K)}\right)}-1
$$

onde:

$a_{i j}$ : Taxa mensal da aplicação para o ativo i no momento j;

$r_{j}^{(K)}$ :Taxa de juros livre de risco para K períodos, no momento j;

$S_{j}^{(q K)}$ : Prêmio pelo risco de crédito para o ativo com a qualidade $\mathrm{q}$, para $\mathrm{K}$ períodos no momento j;

$$
R_{i j}^{p}=\left(1-\frac{\left(1+c_{i j}\right)^{K}}{\left(1+r_{j}^{(K)}\right)}\right)
$$

onde:

$c_{i j}$ : Taxa mensal de captação para o passivo i no momento j;

$r_{j}^{(K)}$ :Taxa de juros livre de risco para K períodos, no momento j;

\subsection{Restrições}

As restrições consideradas no modelo são classificadas em quatro categorias: restrições de políticas internas, restrições contábeis, restrições legais e restrições de mercado.

\subsubsection{Restrições de POLÍtICAS INTERNAS}

Compreendem a modelagem dos aspectos referentes ao risco e liquidez do banco na visão de seus administradores. Embora esses sejam aspectos contemplados nas restrições legais impostas pelos reguladores ao sistema como um todo, as instituições bancárias têm preferências e instrumentos de mensuração diferenciados para captar as peculiaridades específicas de seu negócio e as expectativas quanto ao comportamento futuro do mercado em que atuam.

Nesse sentido, o modelo proposto contempla os seguintes aspectos: o risco relativo à possibilidade de variação, ao longo do horizonte de planejamento, da medida que orienta a tomada de decisão, ou seja, o VPL esperado das alternativas de investimento; a perspectiva gerencial quanto ao risco de crédito assumido em função das decisões presentes e passadas e o dimensionamento da liquidez necessária às operações da instituição.

\section{A) Variação no VPL ESPERAdo}

Para calcular a magnitude de uma possível variação no VPL, será considerada a volatilidade da taxa de desconto livre da parcela relativa ao prêmio pelo 
risco de crédito. Tal variação é calculada por meio da construção de blocos, a partir do agrupamento de fluxos e influxos esperados de caixa com mesma maturidade e mesmo perfil de risco. Para isso, é necessário agrupar todos os fluxos de mesma maturidade (bloco de maturidade $\mathrm{K}$ ) de cada um dos ativos e passivos i decididos no momento j.

De acordo com o modelo VaR Paramétrico, a máxima variação adversa no VPL de cada bloco de maturidade $\mathrm{K}$ pode ser representada pela expressão:

$$
\operatorname{VaR}_{j}^{(K)}=\left[V P_{j}^{(K)}\right]^{\mathrm{T}} \times\left[\delta_{j}^{(K)}\right] \times \sigma_{j}^{(K)} \times z
$$

$\delta_{i}^{(K)}=\frac{-D}{\left(1+r_{i}^{(K)}+s_{i}^{(q K)}\right)}$ para os ativos;

$\delta_{j}^{(K)}=\frac{-D}{\left(1+r_{j}^{(K)}\right)}$ para os passivos;

$$
\left[\delta_{j}^{(K)}\right]=\left[\begin{array}{c}
\frac{-1}{\left(1+r_{j}^{(K)}+s_{j}^{(q K)}\right)} \\
\frac{-1}{\left(1+r_{j}^{(K)}+s_{j}^{(q K)}\right)} \\
\frac{-1}{\left(1+r_{j}^{(K)}+s_{j}^{(q K)}\right)} \\
\frac{-1}{\left(1+r_{j}^{(K)}\right)} \\
\frac{-1}{\left(1+r_{j}^{(K)}\right)} \\
\frac{-1}{\left(1+r_{j}^{(K)}\right)}
\end{array}\right]_{N+M}
$$

onde:

$\left[V P_{j}^{(K)}\right]$ :Vetor de valor presente líquido dos fluxos de caixa de maturidade $\mathrm{K}$ no momento $\mathrm{j}$ incluindo todos os ativos e passivos;

$$
\begin{aligned}
{\left[\delta_{j}^{(K)}\right]: } & \text { Vetor composto pela sensibilidade do } \\
& \text { valor presente à taxa de desconto } r_{j}^{(K)} \\
& \text { de cada ativo e passivo; } \\
\sigma_{j}^{(K)}: & \text { Volatilidade (desvio-padrão) da taxa de } \\
& \text { desconto } r_{j}^{(K)} \text { calculada no momento j. } \\
\mathrm{z}: & \text { Quantidade de desvios-padrão. }
\end{aligned}
$$

Considerando o efeito da correlação entre as taxas de desconto de cada período, a variação máxima no valor presente do conjunto de decisões a serem tomadas no momento j (VaRj) pode ser calculada pela expressão:

$$
\begin{gathered}
\operatorname{VaR}_{j}=\sqrt{\left[V_{j}\right]^{\mathrm{T}} \times\left[C_{j}\right] \times\left[V_{j}\right]} \\
{\left[V_{j}\right]^{\mathrm{T}}=\left[\operatorname{VaR}_{j}^{(1)} \operatorname{VaR}_{j}^{(2)} \cdots \operatorname{VaR}_{j}^{(K)}\right]}
\end{gathered}
$$

$$
\begin{gathered}
{\left[C_{j}\right]=\left[\begin{array}{ccc}
1 & \rho_{12 \ldots} & \rho_{1 k} \\
\rho_{21} & 1 \ldots \ldots \ldots & \rho_{2 k} \\
\rho_{k 1} & \ldots \ldots . . & 1
\end{array}\right]} \\
{\left[V_{j}\right]=\left[\begin{array}{c}
\operatorname{VaR}_{j}^{(1)} \\
\operatorname{VaR}_{j}^{(2)} \\
\vdots \\
\operatorname{VaR}_{j}^{(K)}
\end{array}\right]}
\end{gathered}
$$

onde:

$$
\begin{aligned}
& {\left[V_{j}\right]=\text { Vetor composto pelo } \mathrm{VaR} \text { de cada bloco }} \\
& {\left[C_{j}\right]=\begin{array}{l}
\text { Matriz de correlação das taxas de des- } \\
\text { conto; }
\end{array}} \\
& \rho \mathrm{nm} \text { : Coeficiente de correlação entre a taxa de }
\end{aligned}
$$

A formalização da restrição de risco deve depender da magnitude aceitável pela instituição em relação à variação no valor presente líquido esperado de suas decisões. Assim, numa perspectiva econômica, considerando que as variações de valor na carteira de ativos e passivos causam impacto sobre o 
capital da instituição, a definição desse limite deve ser estabelecida em relação à capacidade da instituição em absorver esses impactos. A exemplo dos modelos propostos para adequação de capital, o limite deve ser considerado em relação ao patrimônio líquido existente em cada período:

$$
V a R_{j} \leq \eta P L_{j}
$$

onde:

$\operatorname{VaR} R_{j}$ : Valor econômico em risco no momento j;

$\eta$ : Fator de alavancagem de $\mathrm{PL}_{\mathrm{j}}$;

$P L_{j}$ : Patrimônio líquido no momento j.

É importante observar que essa restrição caracteriza o modelo proposto como um modelo probabilístico, uma vez que o valor econômico em risco, calculado pelo método VaR Paramétrico, é uma medida provável, ou seja, representa a variação máxima no VPL com determinado grau de probabilidade. Esse grau de probabilidade é dependente da escolha da quantidade $z$ de desvios-padrão da distribuição de probabilidade das taxas de desconto consideradas.

\section{B) RISCO DE CRÉDITO}

O limite máximo de risco de crédito pode ser introduzido no modelo considerando-se os instrumentos gerenciais existentes na instituição para monitoramento de sua carteira. Os modelos que têm sido desenvolvidos pelas instituições consideram a definição de um fator de ponderação de risco de crédito (FPR) para cada classificação de qualidade dos ativos (qn), cujo somatório da ponderação não pode exceder um determinado percentual do capital. Para definição desse volume de capital, em cada momento de decisão j é necessário considerar também a ponderação dos ativos que estão sendo contratados e dos ativos adquiridos em períodos anteriores que remanescem no balanço da instituição, em geral registrados pelo seu custo de aquisição.

$$
\begin{gathered}
\sum_{n=1}^{Q} F P R^{q_{n}} A_{j}^{q_{n}} \leq \varphi P L_{j} \\
A_{j}^{q_{n}}=\sum_{i=1}^{N} \sum_{t=1}^{j} X_{i t}^{p q_{n}} \quad, \quad p=(I, k) \text { para } k \geq j-t+1
\end{gathered}
$$

onde:

Q: Número máximo de classificação (rating) considerado;

$F_{P R}^{q_{n}}$ : Fator de ponderação de risco para a qualidade de crédito qn ;

$q_{n}$ : Classificação da qualidade de crédito;

$A_{j}^{q_{n}}$ : Somatório dos ativos de qualidade qn no momento j;

$\varphi$ : Constante que representa o risco de crédito definido pela instituição;

$P L_{j}$ : Patrimônio líquido no momento j.

\section{C) Constituição de Reservas de Liquidez}

A manutenção de um nível adequado de liquidez é um dos aspectos mais relevantes da gestão bancária. A definição do limite mínimo de ativos a serem constituídos sob o título de Reservas de Liquidez $(R L)$ depende da análise das características internas da instituição e também do comportamento das variáveis macroeconômicas. A cada período j do horizonte de planejamento é necessário obter estimativas sobre a instabilidade dos saldos das contas de depósitos e das demandas por novos empréstimos, bem como realizar previsões sobre os fluxos de ingressos e saídas de caixa decorrentes das operações ativas e passivas contratadas em períodos anteriores.

A formalização do limite mínimo de liquidez pode ser descrita por meio da seguinte expressão:

$R L_{j} \geq \cup D V_{j}+\psi C P_{j}+\sum_{i=1}^{N} \sum_{t=1}^{j-1} F_{i t}^{(j-t)} X_{i t}-\sum_{i=1}^{M} \sum_{t=1}^{j-1} f_{i t}^{(j-t)} Y_{i t}$

onde:

$R L_{j}$ : Montante mínimo de reservas líquidas para o período j;

$\checkmark$ : Constante que representa o percentual sobre o montante estimado para $\mathrm{DV}_{\mathrm{j}}$;

$\psi$ : Constante que representa o percentual sobre o montante estimado para $\mathrm{CP}_{\mathrm{j}}$;

$F_{i t}^{(j-t)}$ : Fluxo de caixa do ativo i, de maturidade j-t contratado no momento t;

$f_{i t}^{(j-t)}:$ Fluxo de caixa do passivo i, de maturi- 


\subsubsection{Restrições Contábeis}

O modelo matemático deve incorporar os impactos provocados na estrutura patrimonial da instituição em decorrência das decisões tomadas a cada período do horizonte de planejamento. Embora esse aspecto não possa ser considerado, do ponto de vista econômico, como uma restrição, na linguagem da Programação Matemática os relacionamentos contábeis do balanço da instituição são formulados como restrições do modelo.
O principal relacionamento a ser observado é o equilíbrio entre o montante de obrigações e capital próprio e o total dos ativos. O segundo aspecto a ser considerado é o ajustamento do patrimônio líquido da instituição em cada período.

\section{A) Equilíbrio ContábIL}

A restrição expressa a identidade do balanço contábil, ou seja, total dos ativos igual ao total das obrigações após os ajustamentos do período j:

$$
\begin{aligned}
& R C_{j}+R L_{j}+A N_{j}+\sum_{i=1}^{N} \sum_{t=1}^{j} X_{i t}^{p q}+A P_{j}=D V_{j}+C P_{j}+\sum_{i=1}^{N} \sum_{t=1}^{j} Y_{i t}^{p}+P L_{j} \\
& p=(l, k), \mathrm{com} k \geq j-t+1
\end{aligned}
$$

\section{B) Constituição do Patrimônio Líquido}

O valor do patrimônio líquido em determinado período depende das decisões tomadas tanto no período em questão como em períodos precedentes. As alterações no patrimônio líquido de um período para outro são motivadas por mudanças endógenas relativas a: resultados das operações, reavaliação de ativos, aumentos de capital, pagamentos de dividendos e outros ganhos e perdas de capital realizados no período.

O resultado das operações é composto pelas re- ceitas e despesas provenientes da intermediação financeira, cujos ativos e passivos são considerados como variáveis do modelo, bem como pelas receitas oriundas da prestação de serviços, pelo pagamento de despesas administrativas e de tributos, pelos efeitos da depreciação, entre outras.

Considerando que todos os resultados são reinvestidos e que não ocorrem aumentos de capital nem reavaliação ou alienação de ativos ao longo do horizonte de planejamento, matematicamente temos:

$$
\begin{gathered}
P L_{j}=P L_{j-1}+E_{j} \\
E_{j}=\theta_{j} R C_{j}+\pi_{j} R L_{j}+\tau_{j} A N_{j}+\sum_{i=1}^{N} \sum_{t=1}^{j} a_{i t} X_{i t}^{p q}-\sum_{i=1}^{M} \sum_{t=1}^{j} c_{i t} Y_{i t}^{p}-\varepsilon_{j} C P_{j}+R O_{j} \\
p=(l, k), k \geq j
\end{gathered}
$$

onde:

$P L_{j}$ : Patrimônio líquido no final do período j;

$E_{j}$ : Mudanças endógenas no patrimônio líquido ocorridas durante o período j;

$\theta_{j}$ :Taxa média estimada de rendimento líquido sobre as reservas compulsórias (RC) no período j;

$\pi_{j}$ : Taxa média estimada de rendimento líquido sobre as reservas de liquidez $(\mathrm{RL})$ no período j;

$\tau_{j}$ : Taxa média estimada de rendimento líquido da carteira de ativos de negociação (trading); $a_{i t}$ : Taxa de remuneração do ativo i contratado no momento $t(t=1 \ldots . j)$ e cujas receitas são realizadas no período j;

$\mathcal{C}_{i t}$ : Taxa de remuneração do passivo i contratado no momento $t(t=1 \ldots . . j)$ e cujas despesas são realizadas no período j ;

$\varepsilon_{i j}$ : Taxa média estimada de remuneração dos depósitos em caderneta de poupança (CP) no período j;

$R O_{j}$ : Resultado das demais operações (prestação de serviços/despesas administrativas, etc) realizadas no período $\mathrm{j}$. 


\subsubsection{Restrições Legais}

Os requisitos exigidos pelas autoridades normativas para o funcionamento dos bancos constituem um conjunto de restrições relevantes, cujo cumprimento representa uma variável importante na administração das instituições. As restrições legais consideradas no modelo dizem respeito à constituição das reservas compulsórias e aos limites de imobilização e de capitalização do banco.

\section{a) Reservas Compulsórias}

Os bancos são obrigados a efetuar recolhimentos compulsórios sobre determinados tipos de captação, como depósitos a vista, cadernetas de poupança e depósitos a prazo. A estimativa do volume de reservas compulsórias em cada período depende da definição das alíquotas e dos períodos de cálculo e de recolhimento, que variam conforme as necessidades da política monetária do governo de controlar os meios de pagamento da economia.

Para sua introdução no modelo, em cada momento de decisão j consideramos a estimativa de um percentual sobre a média de saldos diários (MSD) dos fluxos líquidos de depósitos a vista (DV) e poupança (DP). Essas parcelas dos recursos captados pelos bancos não estarão disponíveis para a aplicação em novos negócios durante o período j, sendo retidos sob a forma de reservas compulsórias (RC) junto ao banco central. Matematicamente, a restrição é formulada pela equação:

$$
D C_{j}=D C_{j-1}+\alpha F V_{j}+\beta F P_{j}, j=1 \ldots T
$$

Onde:

$D C_{j}$ : Saldo de depósitos compulsórios no momento j;

$F V_{j}$ : Fluxo líquido médio estimado de depósitos a vista (DV) no período j;

$F P_{j}$ : Fluxo líquido médio de depósitos de poupança (DP) no período j;

$\alpha$ : Constante que representa o percentual médio de recolhimento compulsório sobre o fluxo de depósitos a vista;

$\beta$ : Constante que representa o percentual médio de recolhimento compulsório sobre o fluxo depósitos de poupança;

$D C_{0}$ : Saldo inicial de depósitos compulsórios.

\section{B) IMOBILIZAÇÃo}

O índice máximo de imobilização sobre o capital da instituição é definido pelos reguladores com o objetivo de limitar a aplicação dos recursos próprios em ativos permanentes (nos quais se incluem as contas de Ativos Imobilizados, Investimentos e Ativo Diferido), possibilitando assim um maior nível de capital de giro próprio.

Conforme normatização em vigor (Resolução no 2669 de 25.11.99), o total de recursos aplicados no Ativo Permanente não pode ultrapassar $80 \%$ do valor do patrimônio líquido ajustado (PLA). Ainda de acordo com o normativo, esse limite deverá ser reduzido gradualmente pelas instituições até atingir o percentual de $50 \%$ a partir de 31 de dezembro de 2002.

A restrição é formulada da seguinte forma:

$$
A P_{j} \leq \omega P L_{j}
$$

onde:

$$
\begin{aligned}
& A P_{j} \text { : Ativo permanente no momento j; } \\
& \omega \text { : Índice máximo para aplicação em } \mathrm{AP}_{\mathrm{j}} ; \\
& P L_{j} \text { : Patrimônio líquido no momento j. }
\end{aligned}
$$

\section{c) Adequação de Capital}

As exigências relativas à adequação de capital constituem um dos temas mais polêmicos no momento atual das instituições financeiras. As recomendações do Comitê da Basiléia vêm promovendo, no mundo todo, inúmeras inovações na regulamentação sobre o nível de capital exigido para suportar os riscos da carteira dos bancos.

No Brasil, a Resolução no 2099/94 regulamentou a matéria estabelecendo que o montante das posições em ativos (incluídos ou não no balanço), cada qual ponderado por um fator de risco específico (FPR), não poderia exceder um limite de alavancagem do patrimônio líquido (PLA). Posteriormente, as Circulares no 2784/ 97 e no 2606/99 alteraram a fórmula de cálculo do patrimônio líquido exigido (PLE), introduzindo fatores de risco diferentes para cobertura do risco de crédito de operações de swap e de câmbio. Recentemente, a Resolução no 2692, de 24.02.2000, regulamentada pela Circular no 2972, de 23.03.2000, introduziu também a exigência de capital para cobertura do risco de mercado decorrente de oscilações nas taxas de juros das operações prefixadas em moeda nacional. 
A restrição referente à exigência de patrimônio líquido para cobertura do risco de crédito da estrutura de ativos no momento j e também para cobertura do risco de mercado de operações específicas, de acordo com os parâmetros da normatização em vigor, pode ser formulada pela seguinte expressão:

$$
F\left(A P R_{j}\right)+F^{\prime} W_{j}+F^{\prime \prime} C_{j}+E C_{j} \leq P L_{j}
$$

onde:

$F$ : Índice de capitalização relativo ao APR (equivalente à 0,11 );

$A P R_{J}$ : Ativo ponderado pelo risco no momento j. É obtido pelo somatório do valor dos títulos do Ativo Circulante, Realizável a Longo prazo, Ativo Permanente e Coobrigações e Riscos em Garantias Prestadas multiplicados pelos seus fatores de risco correspondentes;

$F^{\prime}$ : Índice de capitalização relativo a W (equivalente a 0,20 );

$W_{j}$ : Risco de crédito das operações de Swap no momento j;

$F^{\prime \prime}$ : Índice de capitalização relativo à $\mathrm{C}$ (equivalente à 0,50 );

$C_{j}$ : Operações com ouro e cambiais no momento j;

$E C_{j}$ : Parcela de capital para cobertura do risco de mercado de taxa de juro das operações prefixadas em Real no momento j.

$P L_{j}$ : Patrimônio líquido no momento j;

\subsubsection{Restrições de Mercado}

As restrições de mercado expressam o julgamento da administração com relação aos limites máximos e mínimos para captação e aplicação em cada variável do modelo. A definição desses limites depende da capacidade da instituição em obter previsões sobre o comportamento da econo- mia e sobre suas participações de mercado. Matematicamente, temos:

$$
\begin{gathered}
Y_{M_{I N}} \leq Y_{i j}^{p} \leq Y_{M A X_{i}} \\
X_{M_{M I N}} \leq X_{i j}^{p q} \leq X_{\text {MAX }_{i}}
\end{gathered}
$$

onde:

$Y_{i j}^{p}:$ Montante de captação do passivo i no mo-
mento j; $Y_{M A ́ X}:$ Captação máxima do passivo i;

$Y_{M I N_{i}}$ : Captação mínima do passivo i;

$\begin{array}{ll}X_{i j}^{p q} \text { : Montante de aplicação no ativo i no mo- } & \text { mento }\end{array}$ $X_{M_{I N}}$ : Aplicação mínima no ativo i;

$X_{M A X_{i}}$ : Aplicação máxima no ativo i.

\subsection{Estrutura do MOdelo matemático}

De acordo com a formulação da função objetivo e das restrições definidas, a estrutura do modelo matemático de otimização proposto é apresentada na FIGURA 1.

O modelo matemático proposto para o problema é caracterizado como um modelo de Programação NãoLinear, multiperiódico e probabilístico. A função objetivo é linear, contudo a restrição que expressa a política interna da instituição referente ao risco (restrição (2), da FIGURA 1 é não linear e utiliza dados probabilísticos, relativos à distribuição de probabilidade das variações das taxas de desconto dos fluxos de caixa das variáveis de decisão consideradas. Para as demais variáveis e coeficientes utilizados pelo modelo pressupõem-se valores determinados com certeza (determinísticos). Além disso, as demais restrições são modeladas por equações lineares. 
Figura 1. Estrutura do Modelo Proposto

$$
\begin{aligned}
& \text { FUNÇÃO OBJETIVO: } \quad \text { Max_Z }=\sum_{i=j}^{N} \sum_{j=1}^{T} S_{i j}^{p q} X_{i j}^{p q}+\sum_{i=1}^{M} \sum_{j=1}^{T} R_{i j}^{p} Y_{i j}^{p} \\
& \text { VARIAÇÃO DO VPL } \\
& V a R_{j}-\eta P L_{j} \leq 0 \\
& \text { RISCO DE CRÉDITO } \\
& \text { RESERVAS DE LIQUIDEZ } \\
& \sum_{n=1}^{Q} F P R^{q_{n}} A_{j}^{q_{n}}-\varphi P L_{j} \leq 0 \\
& R L_{j}-\mathrm{v} D V_{j}-\psi C P_{j}-\sum_{i=1}^{N} \sum_{J=1}^{j-1} F_{i j}^{(j-J)} X_{i j}+\sum_{i=1}^{M} \sum_{J=1}^{j-1} f_{i j}^{(j-J)} Y_{i j} \geq 0
\end{aligned}
$$

EQUILÍBRIO CONTÁBIL

$$
R C_{j}+R L_{j}+A N_{j}+\sum_{i=1}^{N} \sum_{J=1}^{j} X_{i j}^{p q}+A P_{j}-D V_{j}-C P_{j}-\sum_{i=1}^{N} \sum_{J=1}^{j} Y_{i j}^{p}-P L_{j}=0
$$

CONSTITUIÇÃO DO PATRIMÔNIO LÍQUIDO

$$
P L_{j}-P L_{j-1}-E_{j}=0
$$

COMPULSÓRIO

$$
D C_{j}-D C_{j-1}-\alpha F V_{j}-\beta F P_{j}=0
$$

IMOBILIZAÇÃO

$$
A P_{j}-\omega P L_{j} \leq 0
$$

ADEQUAÇÃO DE CAPITAL

$$
F\left(A P R_{j}\right)+F^{\prime} W_{j}+F^{\prime \prime} C_{j}+E C_{j}-P L_{j} \leq 0
$$

RESTRIÇÕES DE MERCADO

$$
\begin{aligned}
Y_{i j}^{p}-Y_{M A X_{i}} & \leq 0 \\
Y_{M I N_{i}}-Y_{i j}^{p} & \leq 0 \\
X_{i j}^{p q}-X_{M A X_{i}} & \leq 0 \\
X_{M I N_{i}}-X_{i j}^{p q} & \leq 0
\end{aligned}
$$

O tamanho e a estrutura do modelo são uma função do grau de detalhamento que o banco quer adotar em seu planejamento. Na modelagem proposta, a quantidade de períodos $(\mathrm{T})$ do horizonte de planejamento, bem como a quantidade de categorias de ativos $(\mathrm{N})$ e passivos $(\mathrm{M})$ que serão consideradas no modelo são dados a serem definidos. Além disso, a quantidade de variáveis de decisão do modelo pode ser significativamente ampliada de acordo com as múltiplas possibilidades de se caracterizarem os ativos em relação aos perfis ( $p$ ) e qualidade de crédito (q). A quantidade e o perfil das variáveis de decisão também têm impacto sobre o número de restrições que serão consideradas em cada período. 


\section{CONCLUSÕES}

Neste trabalho foi abordada a problemática do planejamento da composição do balanço bancário por meio da proposta de utilização de uma ferramenta quantitativa. Como objeto fundamental da pesquisa foi construído um modelo de programação matemática, caracterizado pela formulação de uma função objetivo e de um conjunto de restrições, para representar o critério de decisão dos gestores bancários diante de alguns pressupostos ideais de gestão.

A construção do modelo matemático proposto considerou o problema de obtenção da composição de ativos e passivos que fornece o maior valor presente líquido para a instituição, levando em conta, ainda, a necessidade de compatibilizar os aspectos restritivos inerentes ao processo decisório dos gestores bancários.

A forma de representação das variáveis de decisão, por meio da identificação de seus perfis e da sua qualidade de crédito, foi adotada com o intuito de evidenciar os dados necessários para a mensuração do valor presente líquido proporcionado pelas alternativas individuais e, também, para a mensuração do risco incorrido na escolha do conjunto de alternativas. Essa representação foi motivada pela necessidade de agregação das variáveis do modelo, não quanto a produtos específicos, e sim em relação a categorias caracterizadas pela distribuição temporal de fluxos de caixa e pela classificação de qualidade de crédito.

A principal restrição abordada no modelo é a limitação de capital próprio para cobertura de riscos do portfólio. Esse aspecto é contemplado da perspectiva dos reguladores, por meio da modelagem dos requerimentos normativos de capital, e, da perspectiva dos gestores, por meio da proposta de utilização do modelo Var paramétrico, para mensuração do consumo de capital econômico necessário para cobertura do risco de cada conjunto de alternativas sob escolha.

$\mathrm{Na}$ escolha das demais restrições do modelo procuramos contemplar os principais tipos de limitações e relações que devem ser previstas no planejamento de longo prazo da instituição.

Para que o modelo matemático construído seja passível de integrar-se ao processo decisório dos gestores bancários, devem ser observados os se- guintes requisitos relativos ao ambiente institucional:

a) Processo de planejamento: a instituição deve dispor de um processo formal de planejamento periódico, estruturado a partir da definição de cenários macroeconômicos, das estratégias relativas a mercados, produtos e clientes, bem como da análise da sua capacidade produtiva e do potencial de negociação dos seus canais de distribuição. A utilização do modelo matemático deve ocorrer em uma etapa do planejamento em que os grandes delineamentos estratégicos já tenham sido realizados e,em que, coerentemente com a premissa de maximização de valor econômico, a organização esteja preocupada com a quantificação do seu plano de resultados (plano orçamentário) e com a atribuição de metas às diversas unidades organizacionais.

b) Políticas específicas: a instituição deve adotar um conjunto de políticas relativas a risco, liquidez e participação no mercado. Na definição de tais políticas deve ser contemplado o limite mínimo de liquidez, tendo como base previsões sobre os fluxos e influxos de recursos nos períodos de planejamento. Além disso, devem ser estabelecidos os limites de exposição a riscos que a instituição esteja disposta a incorrer, considerando como parâmetro o capital do banco. Os limites máximos e mínimos de negociação de determinadas categorias de produtos devem ser definidos tendo como base o potencial de mercado e as estratégias negociais da instituição.

c) Instrumentos quantitativos: a instituição deve estar preparada para utilizar instrumentos quantitativos sofisticados. Para tanto, deve dispor de pessoal técnico altamente qualificado e de uma cultura gerencial propícia a aceitação de modelos quantitativos para auxiliar a tomada de decisão. Além da compreensão e capacidade de implementação do modelo de programação matemática proposto, os técnicos do banco devem utilizar outras metodologias quantitativas auxiliares - estudo do comportamento das séries temporais de taxas de juros e a adoção de modelos de volatilidade compatíveis com a realidade econômica, construção de curvas de taxas de juros, construção de ratings de crédi- 
to. Possivelmente a concepção desses instrumentos esteja dispersa pela organização e um esforço de integração deve ser empreendido para facilitar a operacionalização do modelo matemático proposto.

d) Definição de responsabilidades: a instituição deve atribuir a gestão do modelo matemático a uma unidade organizacional que possua a responsabilidade de assegurar a otimização dos resultados econômicos da instituição. Essa unidade deve cuidar para que a premissa de incremento de valor econômico seja atendida; coordenar, acionando as diversas áreas intervenientes, o processo de obtenção dos dados de entrada necessários à operacionalização do modelo; integrar o processo de definição das metodologias e instrumentos auxiliares (possivelmente geridos por outras unidades) e deles participar; definir e aplicar o método de resolução adequado ao modelo de programação nãolinear construído; e, fornecer a solução ótima do problema como subsídio ao plano de resultados do banco.

e) Sistema de informações: a instituição deve dispor de um sistema de informações capaz de fornecer os dados de entrada necessários à operacionalização do modelo. São necessários dados mais analíticos sobre a carteira do banco relativamente à previsão da distribuição temporal dos fluxos de caixa das operações a cada período e as suas respectivas taxas de desconto. Também é necessário que o banco mantenha bases históricas de dados que permitam a realização de estimativas sobre os fluxos em contas de depósitos a vista e poupança, percentuais de retenção sob a forma de compulsórios, demandas por empréstimos, entre outros. Outro aspecto importante a ser incorporado ao sistema de informações é a integração do modelo de otimização à ferramenta utilizada pelo banco para simulação das demonstrações financeiras. Assim, a partir da resolução do modelo de programação matemática, a sua solução poderá ser utilizada para projetar as posições patrimoniais e os resultados contábeis de cada período futuro.

O modelo proposto incorpora princípios ideais de administração financeira e aspectos atuais da gestão bancária, podendo constituir-se em uma ferramenta auxiliar no processo de planejamento bancário a qual, no entanto, não substitui a capacidade de julgamento dos administradores. O modelo matemático construído incorpora conceitos e instrumentos de gestão capazes de proporcionar, no processo de decisão referente ao planejamento financeiro, orientação para os gestores bancários na busca de agregação de valor econômico para a instituição.

REFERÊNCIAS BIBLIOGRÁFICAS

ACKOFF, Russel L.; SASIENI, Maurice W. Pesquisa operacional. Rio de Janeiro: LTC - Livros Técnicos e Científicos, 1971.

ASSAF NETO, Alexandre. Matemática financeira e suas aplicações. 4. ed. São Paulo: Atlas, 1998.

BALBIRER, Sheldon D.; SHAW, David. An Application of linear programming to bank financial planning. Interfaces, v.11, n.5, p.77-83, oct. 1981.

BASLE COMMITTEE ON BANKING SUPERVISION. Internacional Convergence of Capital Measurement and Capital Standards, Basle, Switzerland, jul. 1988.
BASLE COMMITTEE ON BANKING SUPERVISION. The Supervisory Treatment of Market Risks, Basle, Switzerland, apr. 1993.

BASLE COMMITTEE ON BANKING SUPERVISION.

Proposal to Issue a Supplement to the Basle Accord to Cover Market Risks, Basle, Switzerland, apr. 1995.

BASLE COMMITEE ON BANKING SUPERVISION. Amendment to the Capital Accord to Incorporate Market Risks. Basle, Switzerland, jan. 1996a.

BASLE COMMITEE ON BANKING SUPERVISION. Overview of the Amendment to the Capital to 
Incorporate Market Risks. Basle, Switzerland, jan. 1996b.

\section{BASLE COMMITEE ON BANKING} SUPERVISION. Supervisory Framework for the Use of 'Backtesting' in Conjunction with the Internal Model Approach to Market Risk Capital Requirements. Basle, Switzerland, jan. 1996c.

BRASIL. Banco Central do Brasil. Circular no 002784 de 27 de novembro de 1997. Divulga novos fatores de risco dos referenciais objeto de operações de "swap" e respectivos coeficientes de correlação para fins de determinação dos riscos de derivativos (RCD) e altera os fatores "F" e "Fф".

BRASIL. Banco Central do Brasil. Circular no 002852 de 3 de dezembro de 1998. Dispõe sobre os procedimentos a serem adotados na prevenção e combate as atividades relacionadas com os crimes previstos na Lei no 9.613 , de 03.03.1998.

BRASIL. Banco Central do Brasil. Circular no 2972 de 23 de março de 2000. Estabelece critérios e condições para a apuração da parcela do Patrimônio Líquido Exigido (PLE) para cobertura do risco decorrente da exposição das operações denominadas em Real e remuneradas com base em taxas prefixadas de juros a variação das taxas praticadas no mercado, de que trata a Resolução no 002692 , de 2000 .

BRASIL. Conselho Monetário Nacional. Resolução no 002099 de 17 de agosto de 1994. Aprova regulamentos que dispõem sobre as condições relativamente ao acesso ao Sistema Financeiro Nacional, aos valores mínimos de capital e patrimônio liquido ajustado, a instalação de dependências e a obrigatoriedade da manutenção de patrimônio liquido ajustado em valor compatível com o grau de risco das operações ativas das instituições financeiras e demais instituições autorizadas a funcionar pelo Banco Central.
BRASIL. Conselho Monetário Nacional. Resolução no 002139 de 29 de dezembro de 1994. Altera a formula de calculo do patrimônio liquido de que trata o Regulamento anexo IV, a Resolução no 2.099, de 17.08.94.

BRASIL. Conselho Monetário Nacional. Resolução no 002399 de 25 de junho de 1997. Altera a fórmula de cálculo do patrimônio líquido de que trata o Regulamento Anexo IV, a Resolução no 2.099, de 17.08.94.

BRASIL. Conselho Monetário Nacional. Resolução no 002606 de 27 de maio de 1999. Estabelece limite para o total de exposição em ouro e em ativos e passivos referenciados em variação cambial, em bases consolidadas, para as instituições financeiras, demais instituições autorizadas a funcionar pelo Banco Central do Brasil e suas controladas diretas e indiretas.

BRASIL. Conselho Monetário Nacional. Resolução no 002669 de 25 de novembro de 1999. Altera o cronograma de redução do limite de aplicação de recursos no Ativo Permanente

BRASIL. Conselho Monetário Nacional. Resolução no 002692 de 24 de fevereiro de 2000. Estabelece critério para apuração do Patrimônio Líquido Exigido (PLE) para cobertura do risco decorrente da exposição das operações registrados nos demonstrativos contábeis a variação das taxas de juros praticados no mercado, para as instituições referidas no Regulamento Anexo IV a Resolução no 002099 de 1994.

BRASIL. Lei no 4595 de 31 de dezembro de 1964. Dispõe sobre a política e as instituições, monetárias, bancárias e creditícias, cria o Concelho Monetário Nacional e dá outras providências.

BRODT, Abraham I. A dynamic balance sheet management model for a canadian chartered bank. Journal of Banking and Finance, v.2, n.3, p.221-241, 1978.

CHAMBERS D.; CHARNES A. Inter-temporal analysis and optimization of bank portfolios. Management Science, v.7, n. 4, p.393-410, jul. 1961. 
COHEN, Kalman J.; HAMMER, Frederick S. Linear programming and optimal bank asset management decisions. Journal of Finance, v.22, n.2, p.147-165, may 1967.

COHEN, Kalman J.; THORE, S. Dynamic balance sheet management: A management science approach. Journal of Bank Research, v.22, p.9-19, 1972.

COHEN, Kalman J.; THORE, S. Programming bank portfolios under uncertainty. Journal of Bank Research, v.1, n.1, p.28-40, 1970.

COHEN, Kalman J.; THORE, S.; MAIER, S. F.; VAN DER WEID, J. H. Recent developments in management science in banking. Management Science, v.27, n.10, p.1097-1119, oct. 1981.

EATMAN, J. L.; SEALEY JR. C. W. A Multiobjective linear programming model for commercial bank balance sheet management. Journal of Bank Research, v.9, n.4, p.227-236, 1979.

ECHOLS, M. E.; ELLIOT, J. W. Forecasting versus allocational efficiency in bank asset planning an integrated evaluation. Journal of Bank Research, v.6, n.4, p.283-295, (winter) 1976.

FABOZZI, Frank J. Measuring and controlling interest rate risk. New Hope: F.J.Fabozzi Associates, 1996.

GÜVEN, S.; PERSENTILI, E. A linear programming model for bank balance sheet management. Omega, v.25, n.4, p.449-459, 1997.

JORION, Philippe. Value at risk. New York: McGrawHill, 1997.

KUMAR, G., Tayi; LEONARD, Paul. Bank balance sheet management: An alternative multi-objetive model. Journal of Operational Research Society, v.39, n.4, p.401-410, 1988.

KUSY, M. I. \& ZIEMBA, W. T. A bank asset and liability management model. Operations Research, n.34, p.356-376, 1986.

MARKOWITZ, Harry . Portfolio selection. New York: John Wiley \& Sons, 1959.
MARTINS, Eliseu; ASSAF NETO, Alexandre. Administração financeira: As finanças das empresas sob condições inflacionárias. São Paulo: Atlas, 1985.

McKINNEY JR. George W. A perspective on the use of models in the management of bank funds. Journal of Bank Research, p.122-127, (summer) 1977.

\section{MORGAN GUARANTY TRUST COMPANY.} RiskMetricsTM - Technical Document. 3. ed. New York, 1995.

REIS, Solange Garcia dos. Planejamento do balanço bancário: Desenvolvimento de um modelo matemático de otimização do retorno econômico ajustado ao risco. São Paulo, 2000. Tese (Doutorado em Controladoria e Contabilidade), Faculdade de Economia, Administração e Contabilidade, Universidade de São Paulo.

RENDER, Barry; STAIR JR., Ralph M. Quantitative analysis for management. 6. ed. New Jersey: Prentice-Hall, 1997.

RODRIGUES, Euchério L. Desenvolvimento e aplicação de um sistema simulador e otimizador no planejamento financeiro de um banco múltiplo brasileiro. Porto Alegre, 1991. Dissertação (Mestrado em Administração), Universidade Federal do Rio Grande do Sul.

ROSS, Stephen A.; WESTERFIELD, Randolph W.; JAFFE, Jeffrey F. Administração financeira. São Paulo: Atlas, 1995.

SAUNDERS, Antony. Financial institutions management: A modern perspective. 2. ed. New York: Irwin, 1997.

SECURATO, José R. Cálculo financeiro das tesourarias: bancos e empresas. São Paulo: Saint Paul Institute of Finance, 1999.

UYEMURA, Dennis G.; VAN DEVENTER, Donald R. Financial risk management in banking. Chicago: Bankline, 1993. 